\title{
NÍVEL DE SERVIÇO NA OPERAÇÃO DE AÇOS LONGOS DA $\mathrm{CSN}^{\star}$
}

\author{
Larissa Manso Miguel Gonçalves ${ }^{1}$ \\ Leo Ferreira da Silva Suisso ${ }^{2}$ \\ Bruno de Carvalho Costa ${ }^{3}$ \\ Marcus Vinícius Damacena da Silva ${ }^{4}$ \\ João Mário Lourenço Filho ${ }^{5}$
}

\section{Resumo}

A partir da latente necessidade de se manter competitivo perante seus concorrentes, as empresas vêm buscando se diferenciar através de inovações e melhoria contínua de processos. Com base nesse conceito a Logística CSN Aços Longos realizou mapeamento dos seus processos para que fosse possível mensurar sua eficiência. Avaliando o ciclo total do pedido através da medição dos tempos de Coleta (entrada do pedido à oferta de veículo), TPV - Tempo de Permanência do Veículo (carregamento) e Entrega (viagem), foi desenvolvida uma ferramenta para medição do Nível de Serviço da operação. Com a constante evolução do mercado e à elevada exigência dos clientes, isso se torna um diferencial, agregando valor aos produtos e fidelizando clientes. A ferramenta contribuiu para melhora significativa na tomada de decisões quanto às atividades críticas e sua consequente contribuição à satisfação dos clientes.

Palavras-chave: Logística; Nível de Serviço; Satisfação dos clientes.

\section{Abstract}

\section{LEVEL OF SERVICE IN THE CSN LONG STEEL OPERATION}

From the urgent need to keep themselves competitive in front of their competitors, the companies have been striving to distinguish themselves through innovations and process continuous improvement. Based on this concept the Long Steel Logistics CSN mapped its process so that it was possible to measure its efficiency. By evaluating the total cycle of the order through the collecting time (the making of the order until the availability of the truck), TPV - Truck Permanence Time (loading) and Delivery (Trip), a tool was developed for the measuring of the operation Service Level. With the constant evolution of the market and the high demand from the customers, this turns a differential, adding value to the products and making the customers loyal. The tool contributed for a significant improvement on taking the decisions concerning the critical activities and their consequent contribution to the satisfaction of the customers.

Keywords: Logistics; Service level; Satisfaction of the customers.

1 Administração de Empresas, Administrador, Analista de Logística, Gerência de Logística de Aços Longos, Companhia Siderúrgica Nacional. Via Sérgio Braga, no-272 - CEP 27260-390 - Ponte Alta, Volta Redonda, RJ, Brasil.

2 Tecnologia em Logística, Tecnólogo em Logística, Analista de Logística, Gerência de Logística de Aços Longos, Companhia Siderúrgica Nacional. Via Sérgio Braga, ํㅡ272 - CEP 27260-390- Ponte Alta, Volta Redonda, RJ, Brasil.

3 Administração de Empresas, Administrador, Analista de Logística, Gerência de Logística de Aços Longos, Companhia Siderúrgica Nacional. Via Sérgio Braga, nº 272 - CEP 27260-390-Ponte Alta, Volta Redonda, RJ, Brasil.

4 Administração de Empresas, Administrador, Gerente de Logística, Gerência de Logística de Aços Longos, Companhia Siderúrgica Nacional. Via Sérgio Braga, no 272 - CEP 27260-390 - Ponte Alta, Volta Redonda, RJ, Brasil.

5 Engenharia Mecânica, Engenheiro, Diretor Operacional de Logística, Diretoria Operacional de Logística, Companhia Siderúrgica Nacional. Av. Faria Lima no 3400 - CEP 04538-132 - Itaim Bibi, SP, Brasil. 


\section{INTRODUÇÃO}

A CSN possui diversos negócios de atuação e há 4 anos atua no negócio de Aços Longos. Sua única fábrica no Brasil desse novo negócio está situada em Volta Redonda/RJ, dentro da Usina Presidente Vargas com capacidade produtiva de 500 mil toneladas/ano. Suas principais matérias primas para o processo de produção são sucata e ferro gusa, adquiridos de fornecedores externos.

A sucata é responsável por $68 \%$ da composição do aço líquido e é recebida na planta através de caminhões carregados, em sua maioria, no estado de São Paulo. Os outros $30 \%$ da composição do aço líquido, o ferro gusa, é proveniente do estado de Minas Gerais e é recebido na planta por vagões. Ambas as matérias-primas são descarregadas num pátio específico destinado a este fim e levadas para abastecimento da Aciaria por vagões de movimentação interna da CSN.

À sucata e ao ferro gusa são acrescidos outros elementos que serão transformados no tarugo, matéria prima para a Laminação.

No forno de reaquecimento, os tarugos são reaquecidos para que sejam laminados em diferentes bitolas em formatos de reto ou rolo (Figura1).

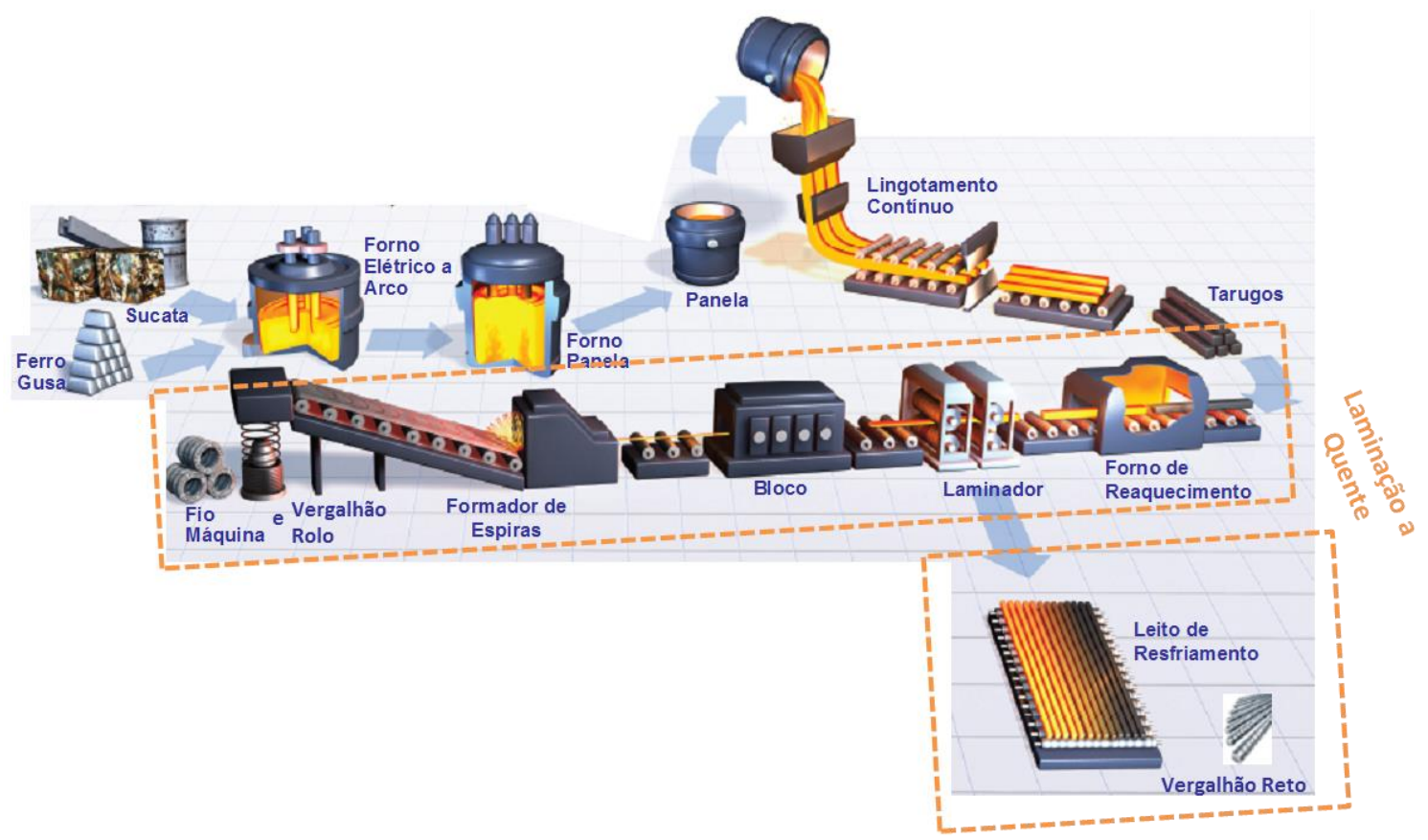

Figura 1. Processo de fabricação de Aços Longos

Após a conclusão do processo de Laminação, os materiais são disponibilizados para a logística armazená-los e posteriormente, embarcá-los via rodovia ou ferrovia. Um percentual dos volumes embarcados na UPV é de vendas diretas ao cliente e o restante transferido as filiais para posterior comercialização. As filiais estão estrategicamente localizadas próximas as áreas geográficas de interesse comercial nos estados de SP e MG (Figura 2). 


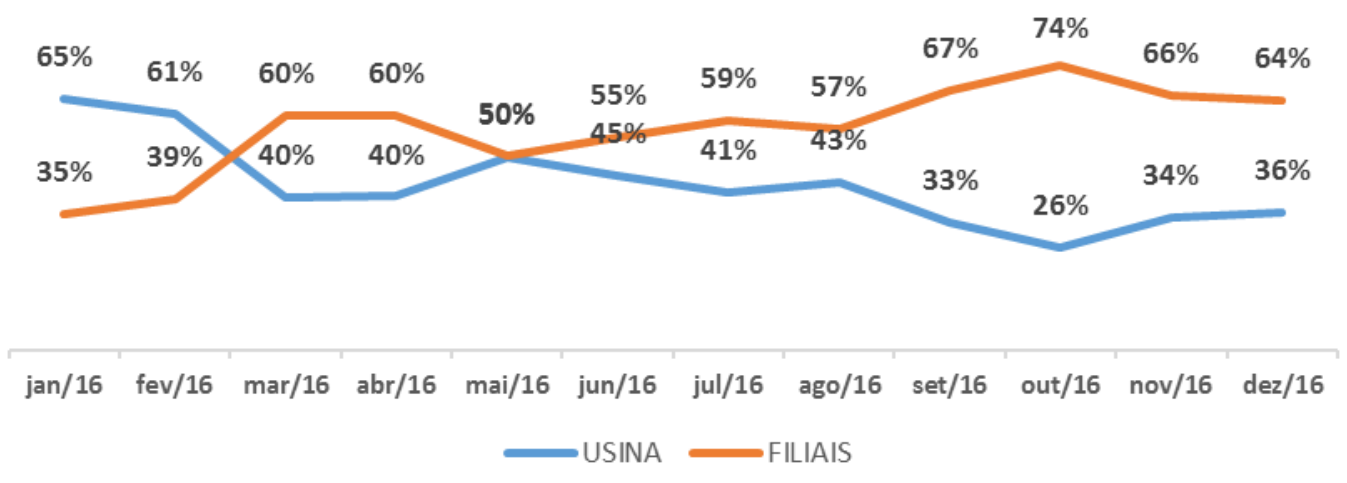

Figura 2. Origem do Faturamento

O avanço de estoque planejado da UPV para as filiais foi decisivo para aumentar o faturamento das mesmas, pois estando mais próximos aos clientes, o atendimento se torna mais eficiente, melhorando o nível de serviço prestado.

Com o objetivo de mensurar esse nível de serviço, que é diferencial competitivo, foi desenvolvido um projeto que visa medir o ciclo total de atendimento aos pedidos à luz dos contratos e acordos comerciais vigentes, para que de forma mais eficaz, os gaps sejam entendidos e tratados.

\section{MATERIAIS E MÉTODOS}

Este trabalho é resultado de reuniões realizadas ao longo do ano de 2016, onde foram discutidos conceitos, ferramentas, dados, ideias e ações com participação do setor comercial e logístico do negócio.

A metodologia adotada foi o PDCA (Figura 3), disseminada por William Edwards Deming desde a década de 50, vêm sendo reconhecida por sua importância para melhoria dos processos. No Brasil, seu propagador foi Vicente Falconi que o adaptou e o descreve como "um método de gestão e o caminho para atingir metas" ou ainda como "um caminho para atingir metas".

No PDCA todo o processo é constituído por atividades que devem ser planejadas e recorrentes, sem que tenham um fim determinado conforme figura abaixo. 


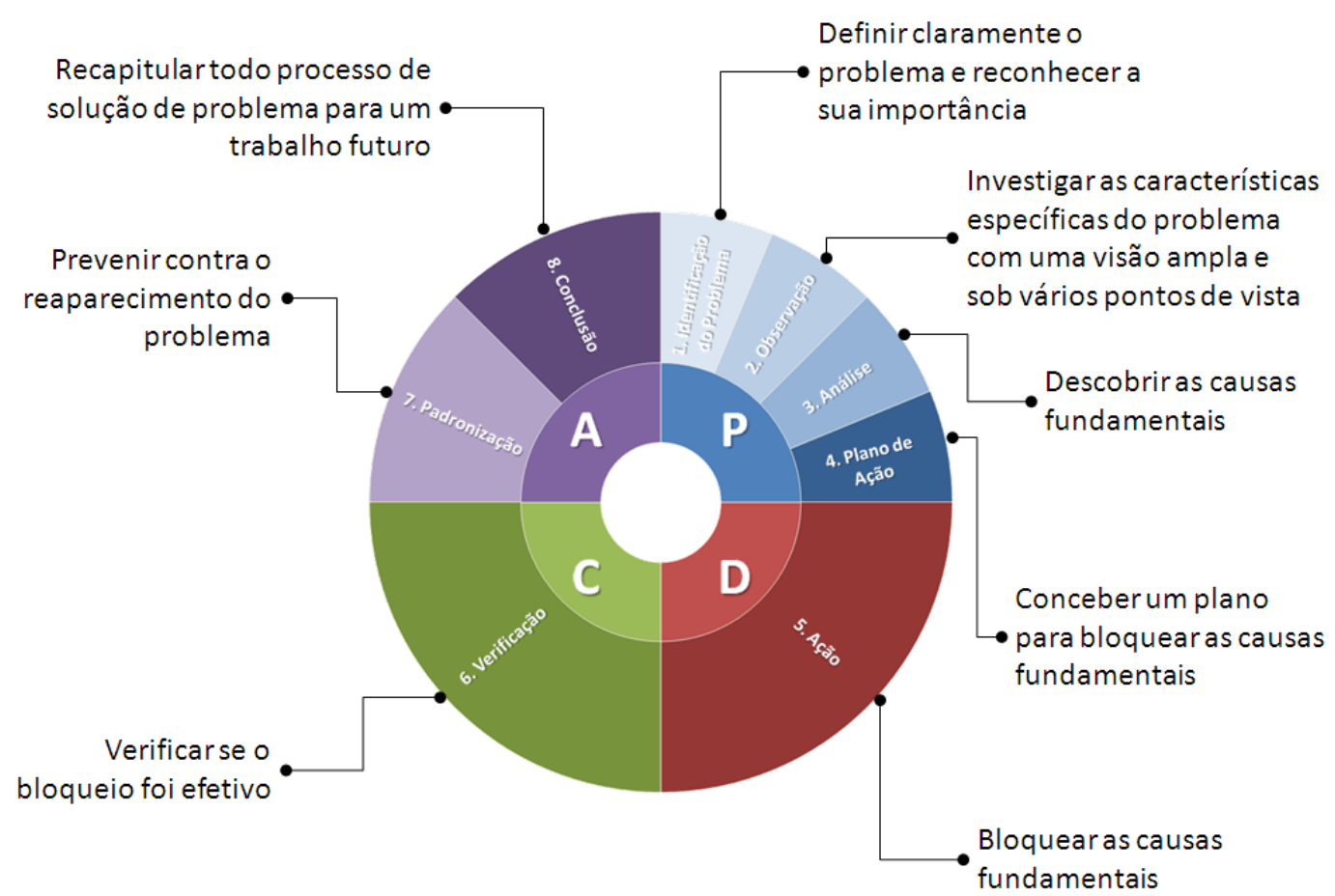

Figura 3. Ciclo PDCA

\subsection{Nível de Serviço}

Para Ballou (1993, p. 73), "O nível de serviço logístico é a qualidade com que o fluxo de bens e serviços é gerenciado. É o resultado líquido de todos os esforços logísticos da firma. É o desempenho oferecido pelos fornecedores aos seus clientes no atendimento dos pedidos. O nível de serviço logístico é fator chave do conjunto de valores logísticos que as empresas oferecem a seus clientes para assegurar sua fidelidade. Como o nível de serviço está associado aos custos de prover esse serviço, o planejamento da movimentação de bens e serviços deve iniciar-se com as necessidades de desempenho dos clientes no atendimento de seus pedidos".

De acordo com esse conceito é preciso considerar que, através do gerenciamento sistêmico do ciclo do pedido é possível mensurar o quanto esse desempenho está contribuindo para a satisfação e fidelização dos clientes. Dessa forma, disponibilizar produtos/serviços no tempo e no local correto é o esforço logístico que gera vantagem competitiva quando devidamente administrado.

\subsection{Nível de Serviço - Ações}

Com o foco na obtenção de resultados confiáveis e administráveis do gerenciamento do Nível de Serviço, foram tomadas diversas ações pelas áreas envolvidas:

Dentro das ações logísticas destacam-se:

- Aprofundar conhecimento dos tempos armazenados no SAP;

- Estabelecer metas e prazos contratuais com o departamento comercial;

- Desenvolvimento de melhorias nos sistemas informatizados;

- Conscientizar transportadores quanto ao cumprimento dos prazos contratuais;

- Garantir que não haja interferências manuais nos documentos gerados no SAP; 
- Gerenciar carteira de pedidos de forma a melhorar o adensamento das entregas conforme origens.

Dentro das ações comercias destacam-se:

- Conscientizar todos os vendedores quanto aos prazos logísticos existentes;

- Equacionar necessidade do cliente com capacidade de atendimento;

- Calendarizar a inserção de pedidos no SAP;

- Garantir a geração de remessas dentro das capacidades de carga e descarga.

\subsection{Nível de Serviço - Premissas e Métricas}

Para atendimento ao ciclo dos pedidos com eficiência, a logística conta com parceiros internos e externos que, em conjunto, têm a responsabilidade do cumprimento de metas gerenciais e ao contrato de prestação de serviços firmado, que seguem:

a) Coleta - Prazo contratual do transportador com a companhia que prevê oferta de veículo num prazo de 48 horas após a geração da remessa - momento em que o Comercial disponibiliza no SAP o pedido e o transportador tem acesso imediato à programação da carga.

b) TPV (Tempo de Permanência de Veículo) - Meta gerencial criada para mensurar o tempo de permanência dos veículos dentro da fábrica, ou seja, o tempo que o veículo se encontra a disposição para carregamento. Esse tempo é medido a partir da oferta de veículo pela transportadora até o momento da emissão da Nota Fiscal. A logística interna possui 5 horas para sua inteira conclusão.

c) Entrega - Prazo contratual do transportador com a companhia calculado com base no cumprimento da Lei no $13.103 / 15$ que regulamenta a profissão de motorista estabelecendo limites para jornada de trabalho e intervalos de descanso. O prazo, medido a partir da emissão da Nota Fiscal até a entrega da mercadoria no cliente, é percorrer $350 \mathrm{~km}$ por dia.

Essas metas e regras são a base comercial para equacionar a necessidade do cliente à capacidade de atendimento logístico de aços longos para que o prazo negociado no momento da venda seja coerente com a realidade de atendimento.

Para que essa eficiência seja medida foi realizado estudo do pedido no SAP considerando todas as etapas até a efetiva entrega ao cliente. Desse estudo foram considerados os seguintes conceitos:

a) Geração da Remessa - Data e hora que o pedido é disponibilizado à logística para embarque.

b) Início do Carregamento - Data e hora que efetivamente o veículo está apto a iniciar o carregamento.

c) Faturamento - Data e hora que é emitida Nota Fiscal, ou seja, o veículo conclui o carregamento.

d) Encerramento - Data e hora em que a carga é entregue ao cliente (essa informação é fornecida pelos transportadores através do comprovante de entrega e inserida no SAP).

\section{RESULTADOS E DISCUSSÃO}

Para medição do Nível de Serviço foi desenvolvida pela Gerência de Logística de Longos uma ferramenta em Excel baseada nos conceitos definidos e dados extraídos do SAP. Gerados de maneira automática, sem intervenção humana, os dados são a 
base para as discussões acerca do atendimento aos clientes do negócio (Figura 4). A ferramenta possui diversas visões para que o Nível de Serviço seja visto por vários aspectos colaborando para a melhoria contínua do processo.

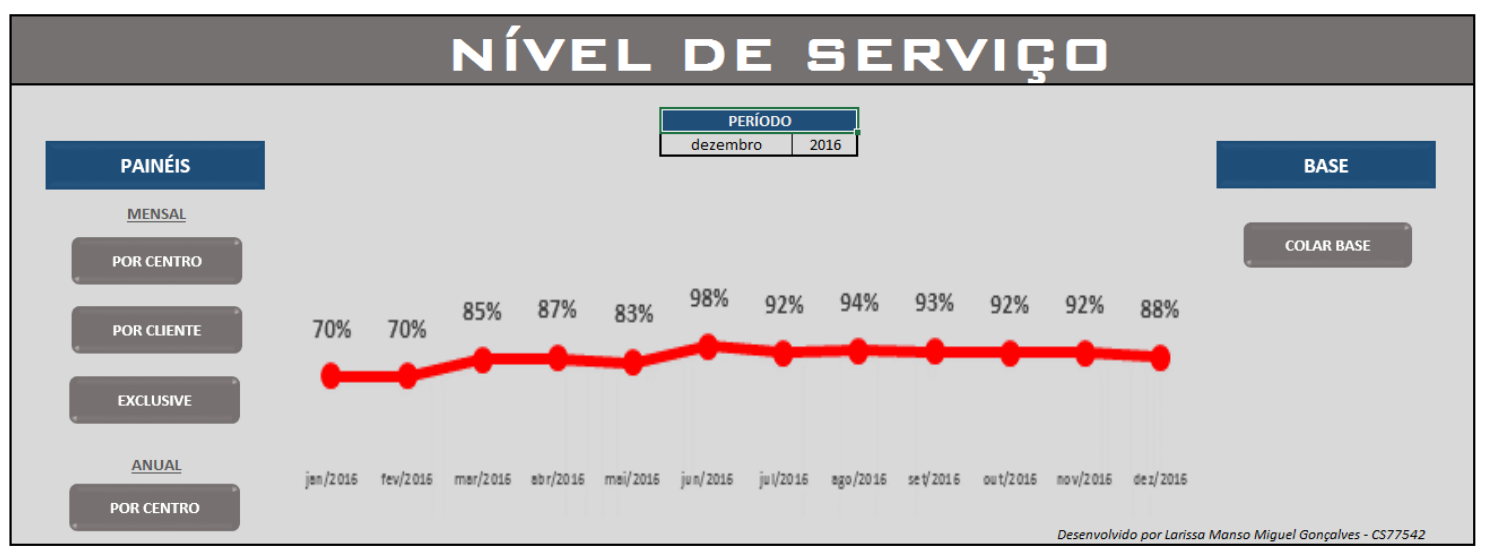

Figura 4. Sistema de medição do Nível de Serviço

Para medir a eficiência, todos os embarques possuem um limite para conclusão, ou seja, a data e hora que deveriam ser concluídos, que é obtido através da soma das metas dos três indicadores secundários: Coleta, TPV - Tempo de Permanência do Veículo e Entrega (Figura 5). Usando a Figura 5 como exemplo, tem-se aproximadamente 97 horas para a entrega da mercadoria desde a sua disponibilização para embarque. Se o processo foi iniciado em 16/01/2017 às 08 horas ele deveria ser concluído até o dia 20/01/2017 às 09 horas.

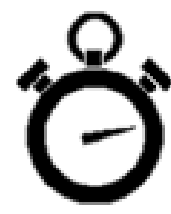

META

48:00:00

05:00:00

44:14:47

TEMPOS

dez/16

42:05:05

5:02:07

42:05:37

Figura 5. Média do tempo de atendimento a cada etapa do Nível de Serviço

Ao somar todo o volume que atendeu ao limite estabelecido e compará-lo ao volume total embarcado, tem-se o \% de Nível de Serviço oferecido aos clientes (Figura 6).
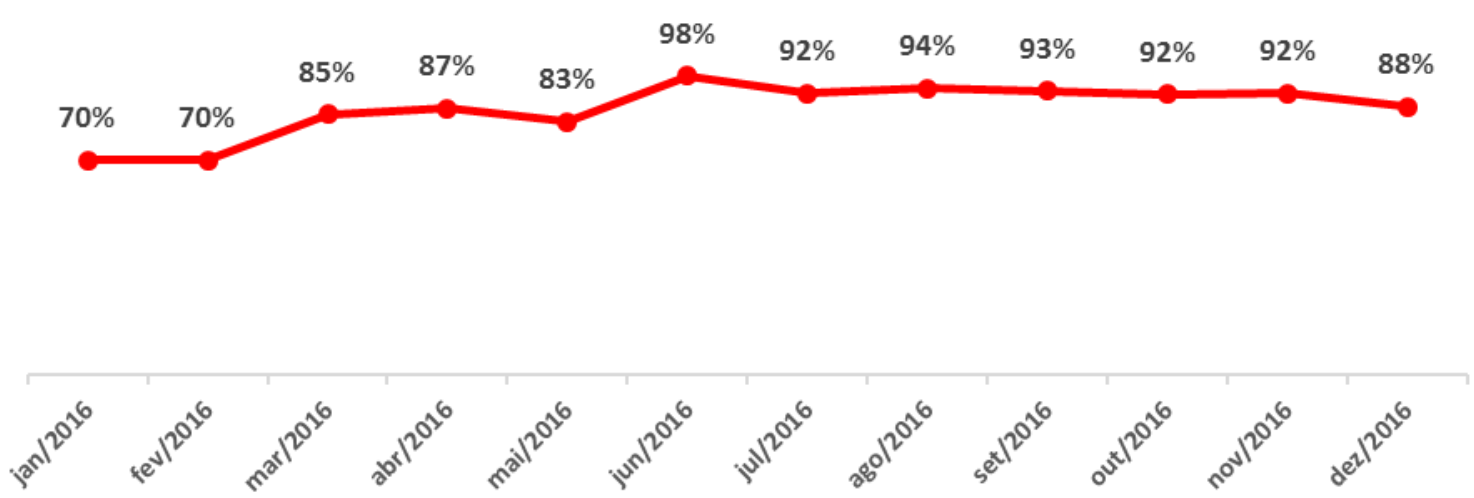

Figura 6. Resultados do Nível de Serviço 
Com o intuito de identificar e solucionar problemas quanto ao Nível de Serviço, sua medição foi particionada para que os indicadores Coleta, TPV e Entrega fossem vistos de maneira separada e detalhada por meio de gráficos secundários que indicassem o possível foco do não atingimento das metas estabelecidas.

No indicador da coleta é mostrado o \% de cumprimento ao prazo de 48 horas para o início do carregamento após a geração das remessas (Figura 7) e o gráfico secundário detalha os tempos de coleta (Figura 8).

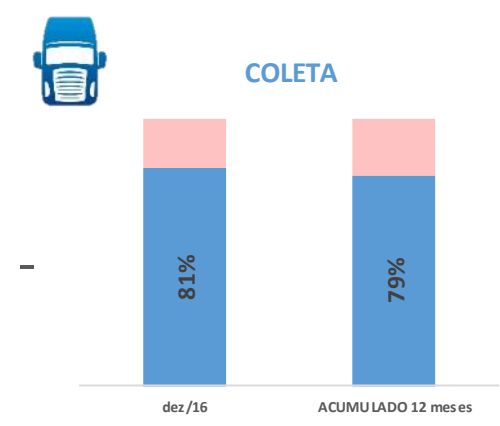

Figura 7. Resultado da Coleta

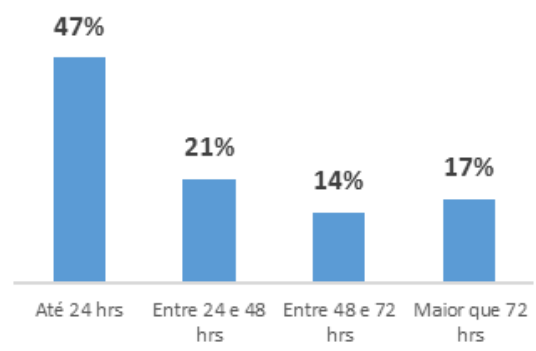

Figura 8. Detalhe da Coleta

No TPV é mostrado o \% de cumprimento ao prazo de 5 horas para carregamento do veículo (Figura 9) e o gráfico secundário detalha os tempos de carregamento (Figura $10)$.

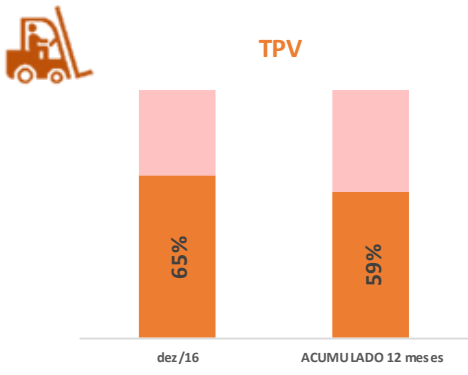

Figura 9. Resultado do TPV

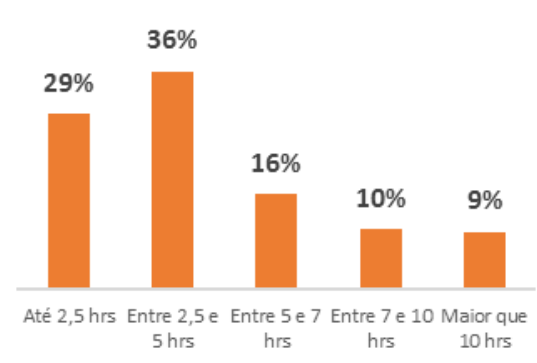

Figura 10. Detalhe do TPV

$\mathrm{Na}$ entrega é mostrado o \% de cumprimento ao prazo de 1 dia a cada $350 \mathrm{~km}$ de distância da origem ao cliente (Figura 11) e o gráfico secundário indica qual a distância dos clientes que o transportador não está conseguindo cumprir o prazo de entrega (Figura 12).

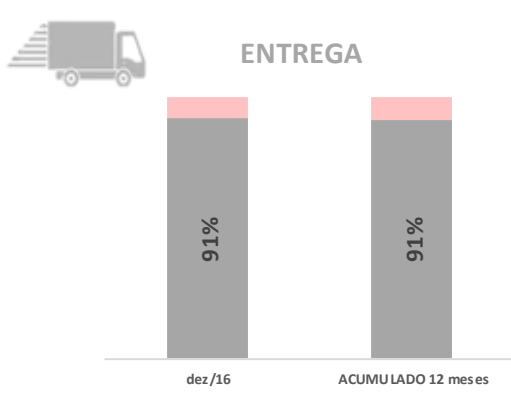

Figura 11. Resultado da Entrega

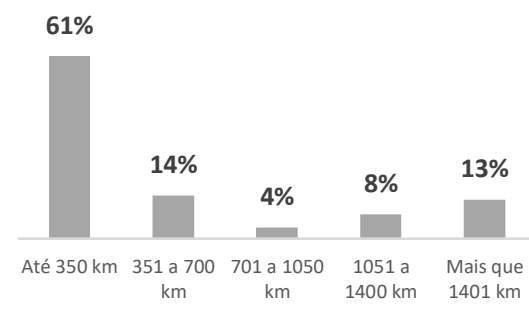

Figura 12. Detalhe do \% não atingido da Entrega 


\section{CONCLUSÃO}

O desenvolvimento das métricas de medição do Nível de Serviço da operação de Aços Longos contribui efetivamente para a tomada de decisões quanto às atividades críticas para que seu impacto seja o menor possível na satisfação dos clientes. Além disso, o contínuo acompanhamento gera melhorias satisfatórias na relação comercial e logística tornando o contato mais amistoso por tratar o cliente como foco.

A melhoria progressiva dos resultados é clara saindo dos $70 \%$ e fechando o ano de 2016 na casa dos $90 \%$. Todo esse processo foi primordial para o desenvolvimento da equipe agregando novos conhecimentos com práticas de melhoria contínua conquistadas através do total controle da operação.

Através da gestão dos resultados obtidos e das melhorias realizadas foi possível alavancar substancialmente 0 nível de serviço prestado aos clientes e consequentemente o aumento de sua satisfação, elevando o grau de confiabilidade da empresa no mercado.

Projetos como este contribuem para o alcance de resultados consistentes que visam a sustentabilidade da empresa e seu contínuo crescimento fazendo cumprir a essência CSN de 'fazer bem, fazer mais e fazer para sempre'.

\section{REFERÊNCIAS}

$1 \quad$ BALLOU, Ronald H. Logística Empresarial: transportes, administração de materiais de distribuição física. São Paulo: Atlas, 1993.

2 BRASIL. Lei no 13.103, de 2 de março de 2015. Dispõe sobre o exercício da profissão de motorista; altera a Consolidação das Leis do Trabalho - CLT, aprovada pelo Decreto-Lei no 5.452, de 10 de maio de 1943, e as Leis nos 9.503, de 23 de setembro de 1997 - Código de Trânsito Brasileiro, e 11.442, de 5 de janeiro de 2007 (empresas e transportadores autônomos de carga), para disciplinar a jornada de trabalho e o tempo de direção do motorista profissional; altera a Lei no 7.408, de 25 de novembro de 1985; revoga dispositivos da Lei no 12.619, de 30 de abril de 2012; e dá outras providências. Brasília, 2015. DOU, 3 de março de 2015. http://www.planalto.gov.br/ccivil 03/ ato20152018/2015/lei/l13103.htm.

3 FALCONI, C. V. Gerenciamento pelas diretrizes. Belo Horizonte: Fundação Christiano Ottoni, 1996. 